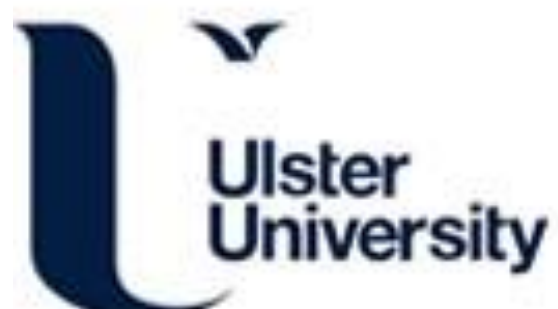

\section{Pressure Effects of an Ignited Release from Onboard Storage in a Garage with a Single Vent}

Brennan, S., Hussein, H., Makarov, DV., Shentsov, V., \& Molkov, V. (2019). Pressure Effects of an Ignited Release from Onboard Storage in a Garage with a Single Vent. International Journal of Hydrogen Energy, 44(17), 8927-8934. https://doi.org/10.1016/j.ijhydene.2018.07.130

Link to publication record in Ulster University Research Portal

\section{Published in:}

International Journal of Hydrogen Energy

Publication Status:

Published (in print/issue): 02/04/2019

DOI:

10.1016/j.ijhydene.2018.07.130

\section{Document Version}

Author Accepted version

\section{General rights}

Copyright for the publications made accessible via Ulster University's Research Portal is retained by the author(s) and / or other copyright owners and it is a condition of accessing these publications that users recognise and abide by the legal requirements associated with these rights.

\section{Take down policy}

The Research Portal is Ulster University's institutional repository that provides access to Ulster's research outputs. Every effort has been made to ensure that content in the Research Portal does not infringe any person's rights, or applicable UK laws. If you discover content in the Research Portal that you believe breaches copyright or violates any law, please contact pure-support@ulster.ac.uk. 


\section{Elsevier Editorial System(tm) for \\ International Journal of Hydrogen Energy \\ Manuscript Draft}

Manuscript Number: HE-D-18-01093R1

Title: Pressure Effects of an Ignited Release from Onboard Storage in a Garage with a Single Vent

Article Type: SI: ICHS2017 (Carcassi)

Section/Category: Safety / Sensors

Keywords: Pressure peaking; enclosure fire; garage; unignited release

Corresponding Author: Dr. Sile Louise Brennan, Ph.D

Corresponding Author's Institution: Ulster University

First Author: Sile Louise Brennan, Ph.D

Order of Authors: Sile Louise Brennan, Ph.D; Harem G Hussein; Dmitriy V Makarov; Volodymyr Shentsov; Vladimir Molkov

Abstract: A numerical study has been performed comparing the hazards, in particular overpressures, arising from the sustained unignited and ignited release from an onboard hydrogen storage tank at 700 bar through a $3.34 \mathrm{~mm}$ diameter orifice, representing a thermally activated pressure relief device (TPRD) in a small garage with a single vent equivalent in area to small window. It has been demonstrated how the overpressure predicted in the case of an unignited release using both CFD and an analytical model is in the region of $0.55 \mathrm{kPa}$ and thus unlikely to cause structural damage. However, the overpressure predicted for the ignited release is two orders of magnitude greater, reaching over $55 \mathrm{kPA}$ in less than $1 \mathrm{~s}$ and thus potentially causing destruction of the structure.

It has been shown that whilst the overpressures resulting from the unignited release are unlikely to cause harm, the garage is engulfed by a flammable atmosphere in less than $1 \mathrm{~s}$ and the oxygen is depleted to levels dangerous to people within this time. In the case of the ignited release, whilst the resultant overpressures are the primary safety concern, it has been shown how the thermal effects resulting from the release extend almost $9 \mathrm{~m}$ from the jet in $1.5 \mathrm{~s}$. 


\section{Highlights}

1. Overpressure due to ignited hydrogen release in a garage examined

2. Pressure due to ignited and unignited release in enclosure compared

3. Pressure from ignited release two orders of magnitude greater than unignited

4. Phenomenon should be considered by regulators and engineers 


\title{
PRESSURE EFFECTS OF AN IGNITED RELEASE FROM ONBOARD STORAGE IN A GARAGE WITH A SINGLE VENT
}

\author{
Brennan, S. ${ }^{1}$, Hussein, H. G., Makarov, D., Shentsov V., Molkov, V. \\ ${ }^{1}$ HySAFER, School of the Built Environment, Ulster University, BT37 0QB, UK \\ sl.brennan@ulster.ac.uk
}

\begin{abstract}
A numerical study has been performed comparing the hazards, in particular overpressures, arising from the sustained unignited and ignited release from an onboard hydrogen storage tank at 700 bar through a $3.34 \mathrm{~mm}$ diameter orifice, representing a thermally activated pressure relief device (TPRD) in a small garage with a single vent equivalent in area to small window. It has been demonstrated how the overpressure predicted in the case of an unignited release using both CFD and an analytical model is in the region of $0.55 \mathrm{kPa}$ and thus unlikely to cause structural damage. However, the overpressure predicted for the ignited release is two orders of magnitude greater, reaching over $55 \mathrm{kPA}$ in less than $1 \mathrm{~s}$ and thus potentially causing destruction of the structure.

It has been shown that whilst the overpressures resulting from the unignited release are unlikely to cause harm, the garage is engulfed by a flammable atmosphere in less than $1 \mathrm{~s}$ and the oxygen is depleted to levels dangerous to people within this time. In the case of the ignited release, whilst the resultant overpressures are the primary safety concern, it has been shown how the thermal effects resulting from the release extend almost $9 \mathrm{~m}$ from the jet in $1.5 \mathrm{~s}$.
\end{abstract}

\subsection{INTRODUCTION}

The commercial use of fuel cell and hydrogen $(\mathrm{FCH})$ technologies is becoming more widespread and they will soon form an essential part of our built environment. There is clear need with emerging technologies that a safety level is maintained which is at least the same as those in existing fossil fuel applications. The number of hydrogen-powered vehicles in use worldwide is growing, and commercialisation is fast approaching a reality, leading to a growth in the necessary indoor use of FCH technologies e.g. material handling, forklifts etc. or parking of these vehicles i.e. in a garage or car park. By understanding the hazards arising due to placement of hydrogen-fuelled vehicles in confined environments, steps can be taken towards reduction of associated hazards and risks by inherently safer design. Indeed, safe indoor use has been the focus of recent investigations, in particular within the HyIndoor Project $[1,2,3]$

In the majority of passenger cars hydrogen is commonly stored as a compressed gas in tanks. Typical storage pressures for vehicle tanks are in the region of 350 bar to 700 bar. Onboard hydrogen storage tanks are required by regulation to be equipped with pressure relief devices (PRDs) [4]. These are fitted to the fuel tank and function by releasing the fluid in the event of an abnormally high temperature, e.g. in conditions of fire. Current PRDs provide rapid release of the hydrogen, thus minimising the possibility of catastrophic failure of the tank during exposure to fire. Existing TPRDs intend to vent the hydrogen before this catastrophic rupture occurs preventing disastrous explosions. High mass flow rates from TPRDs are potentially acceptable outdoors, where the buoyancy of hydrogen is an advantage in aiding dispersion below the lower flammability limit. However, from a safety perspective a number of hazards arise following a high mass flow rate release, characteristic for current TPRDs, in a confined space containing a vent. Previous work on this topic by the authors has focused on the overpressure development within an enclosure due to an unignited release. Preliminary numerical and analytical modelling work on this topic by the authors focused on a hypothetical scenario, with a constant mass flow rate release [5] and the phenomenon of a rapid rise in pressure following the unignited release of hydrogen through a "typical" TPRD (diameter $5.08 \mathrm{~mm}$ ) in an enclosure with a small vent was discovered and explained. It was demonstrated, how for a constant release of $0.39 \mathrm{~kg} / \mathrm{s}$ of hydrogen into a $30.4 \mathrm{~m}^{3}$ garage with a single vent the size of one brick the 
overpressure within the enclosure resulting from the injection of hydrogen reaches a level of 10-20 $\mathrm{kPa}$, capable of destroying the garage, within only $2 \mathrm{~s}$. The high volumetric flow rate of hydrogen results in these significant overpressures even without combustion. For the chosen scenario, if the enclosure does not rupture first, the pressure within the garage, reaches a maximum level in excess of $50 \mathrm{kPa}$ for 350 bar storage and $100 \mathrm{kPa}$ for $700 \mathrm{bar}$. This maximum pressure then drops off and tends towards a steady state value, an order of magnitude lower, and equal to that predicted by the simple steady state estimations. For the very specific case examined it was clear that unacceptable levels of overpressure above 10-20 kPa are reached within a short timeframe of 1-2 $\mathrm{s}$ and subsequent work considered "safe" vent sizes for the "pressure peaking" occurring for the same unignited release rate and enclosure size [6]. The latter work focusing on more "realistic" scenarios, utilising a blow-down model developed at Ulster University to account for mass flow rate decay [7] and suggested "safe" TPRD diameters for enclosures of different volumes with different natural ventilation levels. This previous work, specifically the geometry and scenario considered "safe" for unignited releases forms the basis of the work presented here. The pressure peaking phenomenon for unignited jets, and the predicted overpressures has been validated against laboratory scale experiments [8]. It should be emphasised that the pressure peaking phenomenon is not evident with other, heavier, fuels such as propane. Whilst a small pressure rise is evident for e.g. methane for a comparable leak with minimal ventilation, the peak is almost two orders of magnitude lower than that resulting from the hydrogen leak and unlikely to cause structural damage [5].

To date the work and recommendations concerning pressure peaking have focused solely on unignited releases. In the case of TPRD activation, the most likely cause is fire. Hence, when considering a high mass flow release from a TPRD in an enclosure, the scenario of an ignited release cannot be ignored. There has been limited published work on hydrogen fires in enclosures, and none on numerical simulation of ignited pressure peaking phenomenon, however, it should be noted that there have been many studies on free jet fires as discussed by Molkov and Saffers [9]. Recent work at Ulster has focused on analytical modelling of the problem [8]. In the case of TPRD release, scenarios with an initially high mass flow rate are most representative. However, the most recent experiments on hydrogen fires in enclosures have focused on laboratory scale releases [10] and are being used by the authors for validation of the CFD approach to enclosure fire modelling, with an emphasis on overpressure prediction. This approach has then been applied to a hypothetical scenario where pressure peaking is expected to occur. Whilst recommendations have been presented for TPRD diameters which will prevent dangerous over pressures in the case of an unignited release [6], it is highly likely that the pressure resulting from these "safe" diameters will be significantly higher in the event of an ignited release. Hence, this work is driven by the need to understand the hazards resulting from the rapid ignited release of hydrogen from onboard storage tanks through a TPRD inside a garage-like enclosure with low natural ventilation i.e. the consequences of a jet fire which has been immediately ignited, delayed ignition is not considered here. The resultant overpressure is of particular interest. The pressure peaking phenomenon for an ignited release had not been studied numerically and compared with that for an equivalent unignited release and it should be emphasised that this work has relevance beyond a TPRD scenario and may occur anywhere a momentum driven release occurs in an enclosure with minimum ventilation.

\subsection{PROBLEM DESCRIPTION}

Both an unignited and ignited hydrogen release, from typical onboard hydrogen storage tanks at 700 bar through a TPRD, are considered in a garage type enclosure with a single vent. The hypothetical events involve conservative "quasi-steady" constant mass flow rate releases of $0.2993 \mathrm{~kg} / \mathrm{s}$ through a TPRD diameter of $3.34 \mathrm{~mm}$, pressure drop in the storage tank was not considered. The TPRD opening time was taken as $0.01 \mathrm{~s}$. This diameter is lower and hence potentially "safer" than typical $5.08 \mathrm{~mm}$ diameters. Whilst a smaller diameter minimises the effects of pressure peaking it presents additional challenges in that the fire resistance of the hydrogen tank should be sufficient to account for the longer blow down period, a $3.34 \mathrm{~mm}$ TPRD diameter is reflective of "realistic" values and as shown is a "safe" diameter for the unignited release scenarios considered here. 
A garage with internal dimensions $4.5 \times 2.6 \times 2.6 \mathrm{~m}(\mathrm{~L} \mathrm{x} \mathrm{W} \mathrm{x} \mathrm{H})$ was considered with a single vent, the dimensions of the vent were chosen such the overpressures resulting from an unignited release would be "safe". A vent of $0.35 \times 0.55 \mathrm{~m}(\mathrm{~W} \mathrm{X} \mathrm{H})$ was selected, this is over 7 times greater than that used in the original study [5] and represents an area characteristic of e.g. a small window. The vent was centred and was flush with the ceiling. The release was assumed to occur in the centre of the garage $0.5 \mathrm{~m}$ from the floor. The evolution of flammable mixture formation (unignited case), fire dynamics (ignited case) and over pressure in the garage was examined. It is noted that in order for a TPRD to be normally activated there is likely to be a fire present in the garage, however, this primary fire and the resultant consequences are beyond the scope of this paper. Rather the purpose of the analysis was to compare the hazards purely due to the pressure peak caused by an ignited and unignited release.

\subsection{METHODOLOGY}

CFD was used for both the unignited and ignited cases and the phenomenological model for pressure peaking was used in the unignited case.

\subsection{CFD approach}

The CFD package FLUENT [Error! Reference source not found.11] was the base software tool used to simulate the high-pressure hydrogen release. A 3D domain with dimensions $15.5 \times 6.6 \times 7 \mathrm{~m}(\mathrm{~L} \mathrm{x}$ $\mathrm{W} \times \mathrm{H}$ ) was taken, with a distance of $9 \mathrm{~m}$ from the domain boundary to the vent. A total of 351,152 hexahedral control volumes were used with grid refinement inside the garage. The garage and the domain were assumed to be initially $100 \%$ air at STP. Flow at the PRD exit is supercritical. To avoid the high computational expense of resolving this under-expanded region an Ulster University approach [7] was used to calculate the equivalent diameter of the jet. This approach was used to calculate the parameters of the flow at the notional nozzle, including the mass flow rate. The mass flow rate at the TPRD was assumed to increase linearly to mimic an opening time of $0.01 \mathrm{~s}$. Isentropic flow equations were used to determine the total temperature and pressure at the leak.

The garage floor, walls, and roof were of thickness of $0.15 \mathrm{~m}$ and were assumed to be constructed of concrete. The material properties chosen are similar to brick and concrete typically used for garages in the UK. The front wall, on which the vent is located, was taken as aluminium with a thickness of 0.02 $\mathrm{m}$ to represent the garage door.

Table 1. Material properties used in the garage

\begin{tabular}{|l|l|r|r|}
\hline Materials Properties & Units & Aluminium & Concrete \\
\hline Density & $\mathrm{kg} / \mathrm{m}^{3}$ & 2719 & 2400 \\
\hline Specific heat $(\mathrm{cp})$ & $\mathrm{J} / \mathrm{kg}-\mathrm{K}$ & 871 & 900 \\
\hline Thermal conductivity & $\mathrm{W} / \mathrm{m}-\mathrm{K}$ & 202.4 & 1.5 \\
\hline Refractive index & & 1 & 1 \\
\hline Internal emissivity & & 0.09 & 0.85 \\
\hline
\end{tabular}

A pressure based solver was used with the RNG k- $\varepsilon$ Navier-Stokes (RANS) approach. The PressureImplicit with Splitting of Operators (PISO) approach was used for pressure-velocity coupling [12, 13]

In the case of the ignited release the discrete ordinates method was used to account for radiation and the Eddy Dissipation Concept (EDC) model was used for combustion [14]. Ignition was modelled as a spark by patching a temperature until it could be confirmed the flame had begun to propagate. This combustion modelling approach has been successfully applied by the authors in previous work and is described in [15], in the work presented here it is extended to compressible flow. In addition to overall convergence, conditions at the boundaries, and mass conservation were monitored. It should be noted that even with the existing mesh, simulations with a CFL of 1 took over one month to reach a time of 
1s. Thus, a more refined mesh was deemed to be prohibitive in terms of computing resources. However, a time dependency study was performed, in all cases the initial CFL was kept below 1 until ignition was initiated and a flame was established. It was found that increasing the CFL up to $10 \mathrm{did}$ not affect the results and this is demonstrated in Section 4.

\subsection{Phenomenological approach}

A system of equations to predict the development of the overpressure within the enclosure with time in the assumption of a perfect stirred reactor (perfect mixing of each released fraction of hydrogen with a mixture already available within the garage) was presented in [5] and predicted overpressures validated in [8]. This model analytical approach has been applied to predict the overpressure in the garage in the case of the unignited release. Work is underway to develop such a model for an ignited release.

\subsection{RESULTS}

The CFD results for both the ignited and unignited release are discussed in the following section, and the pressure dynamics of the unignited case is compared with the analytical prediction.

\subsection{Pressure dynamics}

A comparison of the pressure dynamics predicted using CFD and the phenomenological model for the unignited release are presented in Figure 1. It should be noted that losses are taken into account in the phenomenological model by using a coefficient of discharge $\mathrm{C}=0.6$ for the vent [16]. The coefficient of discharge represents the ratio between the actual flow discharge and theoretical flow discharge and reflects pressure losses through the vent, a value of 1 would represent no losses.

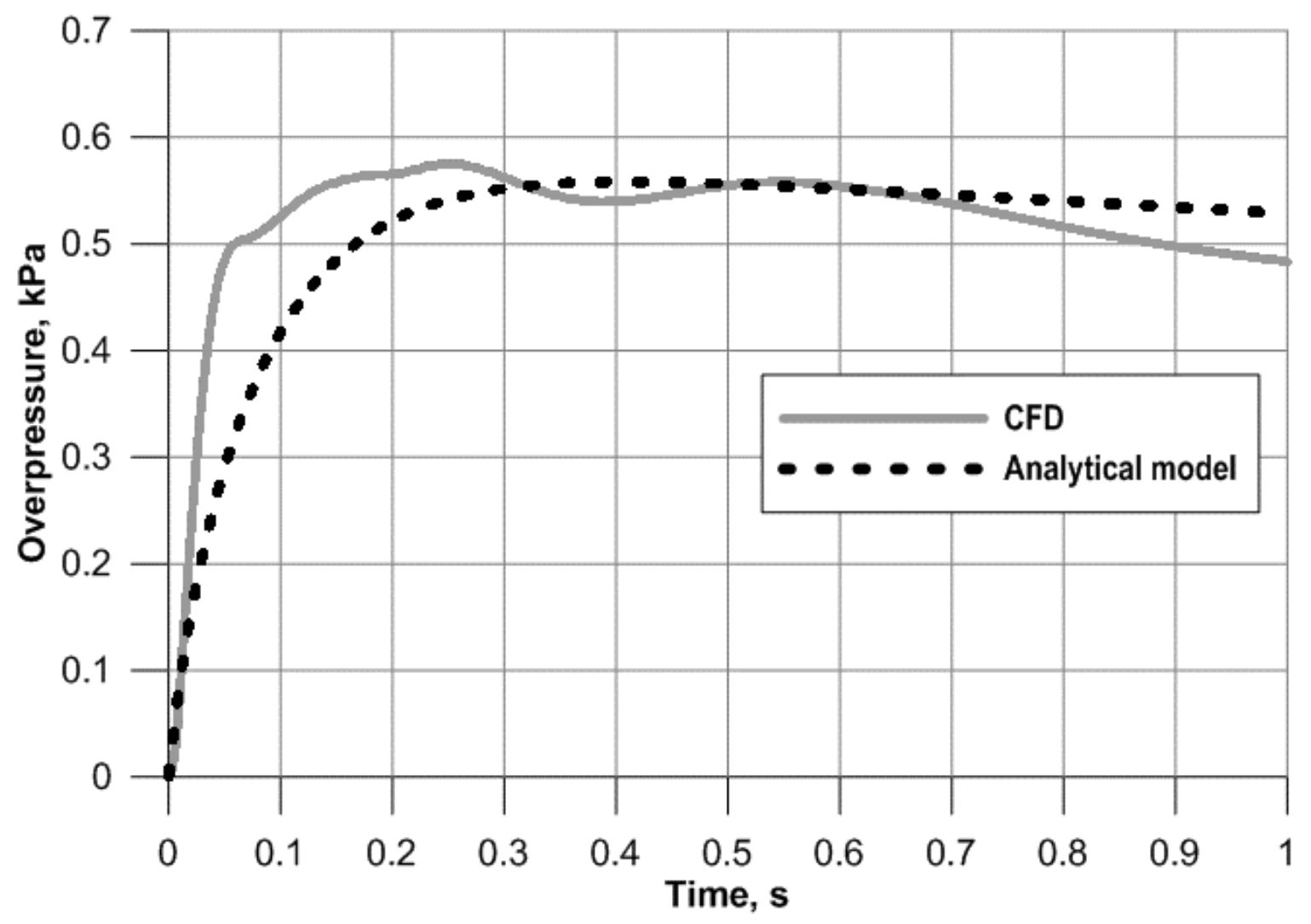

Figure 1. Overpressure in the garage for an unignited release (CFD and analytical model) 
It can be seen how the predictions by the CFD and phenomenological models are within less than $10 \%$ of one another. As mentioned a value of 0.6 was used for the coefficient of discharge in the analytical model, however, it should be noted that a value of 0.59 was found to match the CFD results.

It is evident in Figure 1 how the overpressure predicted by the CFD simulation "dips" between 0.3 and $0.5 \mathrm{~s}$, before rising again, whereas the overpressure predicted by the analytical model follows a smooth curve. This can be explained by examining the composition of the mixture in the garage, and the vicinity of the vent in particular during this period of time. The phenomenological model considers the garage as a perfectly stirred reactor, i.e. the mixture composition is uniform throughout the enclosure. It is assumed the garage is initially $100 \%$ air and eventually $100 \%$ hydrogen. CFD allows for the three-dimensional nature of the flow and the non-uniform distribution within the enclosure. Figure 2 shows the composition (hydrogen, oxygen and nitrogen by volume) within the vent at three points in time $0.25 \mathrm{~s}$ (before dip), $0.37 \mathrm{~s}$ (dip) and $0.58 \mathrm{~s}$ (after dip). It can be seen that the percentage of hydrogen (lighter gas) is somewhat less at $0.37 \mathrm{~s}$ than at $0.25 \mathrm{~s}$ and $0.58 \mathrm{~s}$, whilst the difference is small, the percentage of hydrogen at the vent in the analytical model will grow continuously between $0.25 \mathrm{~s}$ and $0.58 \mathrm{~s}$

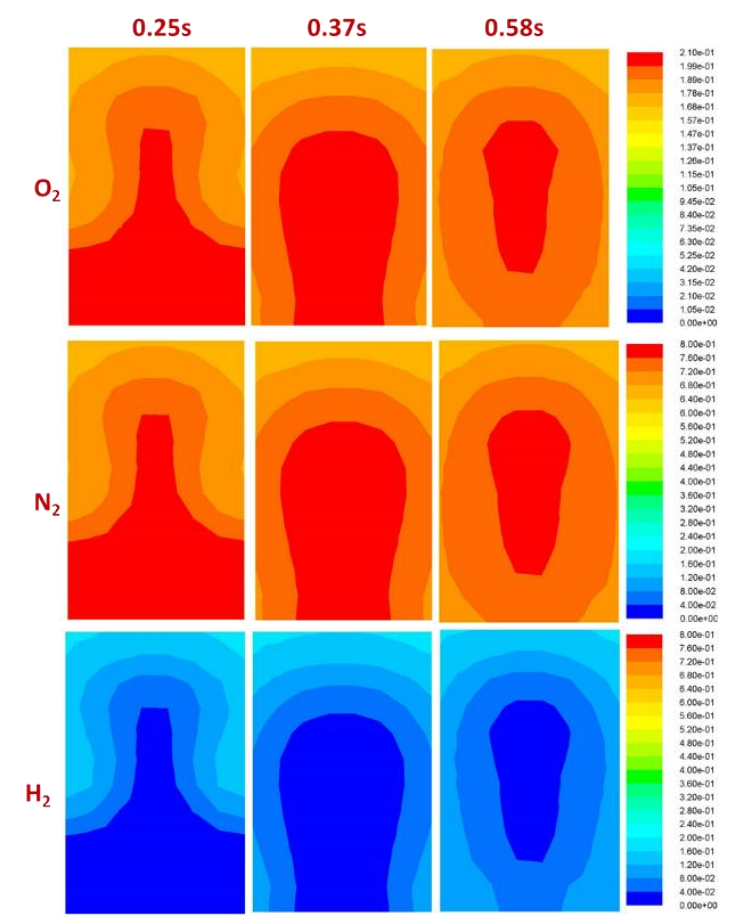

Figure 2. Contours of oxygen, nitrogen and hydrogen mole fraction in the vent area at $0.25 \mathrm{~s}, 0.37 \mathrm{~s}$, and $0.58 \mathrm{~s}$ for the unignited release

It is important to note that the overpressure predicted for the unignited release reaches a maximum value of less than $0.6 \mathrm{kPa}$, this level of pressure would not cause structural damage to the garage [17] and would be deemed "safe". In contrast Figure 3 presents a comparison of the overpressure predicted for both the ignited and unignited scenario. Two sets of numerical results are presented for the ignited case, based on a CFL of 1.2 and of 10 , the results are identical and hence overlap. The CourantFriedrichs-Lewy or CFL number is a function of velocity, cell-size and time step it is an indication of how fluid moves through each cell. For a CFL less than or equal to 1 then the fluid particles move from a maximum of one cell to another in one timestep, for a CFL > 1 then particles move through more than one cell in each time step. The maximum CFL in the domain occur at the leak outlet where the cells are smallest, and the velocity is greatest.

The pressure for the unignited case is negligible compared to the ignited scenario and there is no perceivable peak in pressure when plotted alongside the ignited case. It can be clearly seen in Figure 3 
that the TPRD diameter, vent and leak rate which may seem "safe" when considering an unignited release, do in fact lead to pressures capable of destroying the garage in less than $1 \mathrm{~s}$ [17] in the event that the release is ignited. The overpressure predicted for the ignited release is almost two orders of magnitude greater than that predicted for the unignited case, i.e. 100 times greater. This finding raises safety concerns for existing TPRDs, and indeed any scenario whereby a rapid, ignited release of hydrogen occurs in an enclosure.

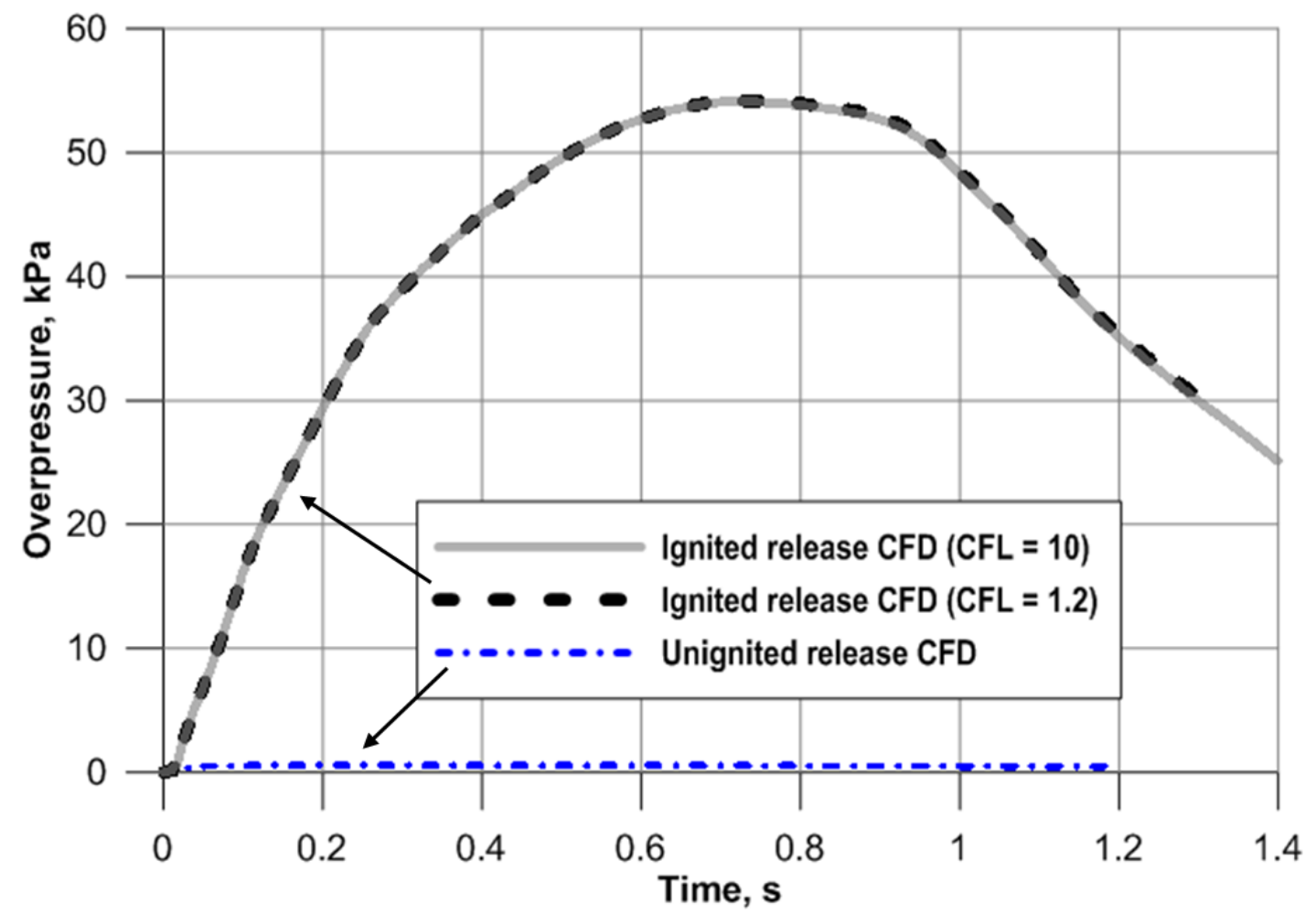

Figure 3. Predicted overpressure in a garage, for both an unignited and ignited release of $0.299 \mathrm{~kg} / \mathrm{s}$

\subsection{Flammable atmosphere for the unignited leak}

The dynamics of flammable hydrogen-air mixture (4-75\% vol.) is considered for the unignited release scenario. The development of a flammable mixture within the enclosure is presented in Figure 4 for the first 1.19 seconds of the release. A 2D slice along the centre axis of the garage is taken, and contours of hydrogen mole fraction between $4 \%$ and $75 \%$ are presented. The formation of a flammable layer can be clearly seen. Within 1 s almost $100 \%$ of the garage is already engulfed by a flammable mixture. 

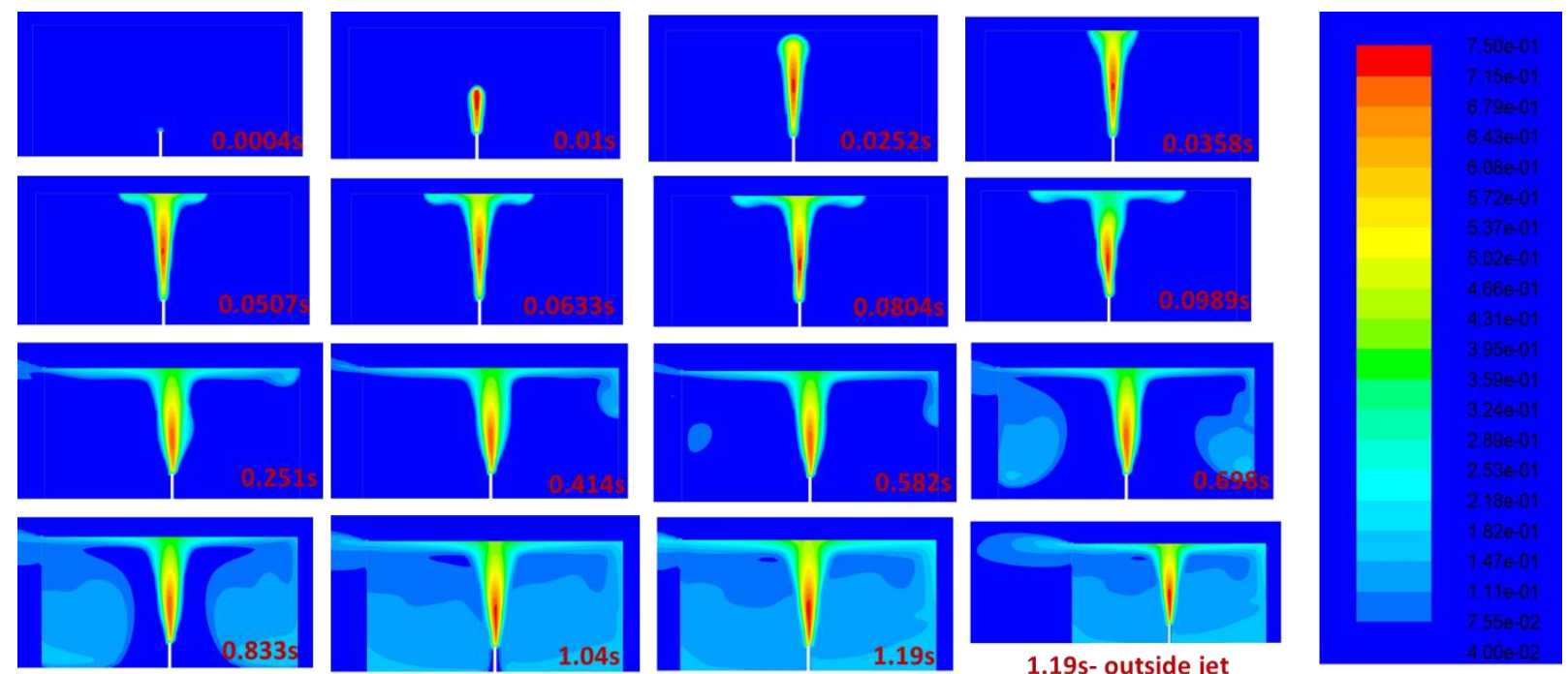

Figure 4. Contours of hydrogen mole fraction between $4 \%$ and $75 \%$ showing dynamics of flammable hydrogen-air mixture formation for an unignited release

As the garage fills with a flammable hydrogen-air mixture the quantity of hydrogen exiting the garage through the vent will increase resulting in a flammable jet outside the garage. This presents an external fire hazard originating from the vent and, in the event of ignition, burn back to the premixed, turbulent, flammable mixture inside the garage will result in a significant explosion hazard. The final image within Figure 4 clearly illustrates the extent of the flammable jet exiting the vent; at a time of $1.19 \mathrm{~s}$ the jet extends approximately $2 \mathrm{~m}$ outside the garage. Thus, it can be shown, how even with a relatively large vent a significant fire and explosion hazard develops outside the garage within $1 \mathrm{~s}$ of the release. This has implications for surrounding people and structures. Development of the flammable jet was not the primary focus of this work; thus the simulation has not been run beyond $1.19 \mathrm{~s}$. However, due to the decreasing pressure inside the enclosure the jet is not expected to grow further horizontally, rather to become buoyancy driven. It should also be emphasised that this scenario represents a very low probability case, i.e. malfunction of the TPRD, as it would be expected that a function TPRD would be thermally activated by the presence of fire and hence ignition would occur.

\subsection{Oxygen depletion for the unignited leak}

It can be seen from the overpressures presented in section 4.1 that in the event of no ignition during a release the structure will not be adversely affected. Again, it should be emphasised that this is a very specific scenario and indeed the likelihood of an individual being present in this case is low, nevertheless for completeness it is worth understanding additional potential human effects of an unignited release. While hydrogen itself is not a toxic gas, the presence of a leak can lead to asphyxiation as a result of oxygen depletion. The physiological hazards due to oxygen depletion are described in [18] where 15-19 percent by volume oxygen is said to lead to "decreased ability to perform tasks; may induce early symptoms in persons with heart, lung, or circulatory problems" and 8-10 percent by volume of oxygen is said to lead to "nausea, vomiting, unconsciousness, ashen face, fainting and mental failure". In the configuration considered, $19 \%$ oxygen by volume is reached with $1 \mathrm{~s}$ as illustrated in Figure 5. Note that at $0 \mathrm{~s}$ the garage has a concentration of $21 \%$ oxygen by volume throughout so the coloured areas in the figure represent the regions where the concentration is decreasing. So whilst the relatively large vent ensures that the garage will withstand the pressure of the unignited release the risk for human to be "trapped" by hydrogen and unable to evacuate is present. 


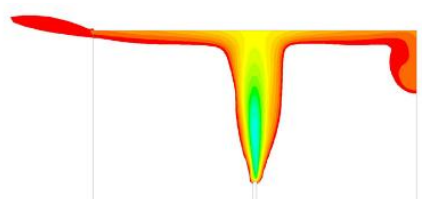

$0.37 \mathrm{~s}$

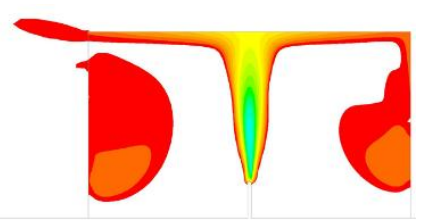

$0.69 \mathrm{~s}$

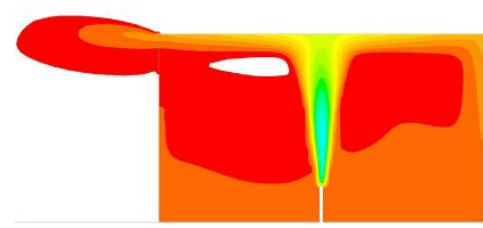

$1.19 \mathrm{~s}$

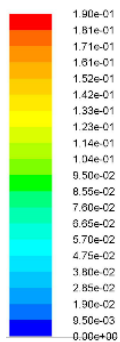

Figure 5. Contours of oxygen mole fraction between $0 \%$ and $19 \%$ with the garage for the first $1 \mathrm{~s}$ of the unignited release

\subsection{Flame development for the ignited release}

It is clear from section 4.1 that the overpressure resulting from an ignited release would be capable of destroying the garage within $1 \mathrm{~s}$, and it is this overpressure, as opposed to the thermal effects which is the most significant safety concern. However, the flame development within, and external to the garage are presented in this section for completeness. Figure 6 illustrates the hydroxyl $(\mathrm{OH})$ contours on a $2 \mathrm{D}$ slice along the centre axis of the garage for the first $2 \mathrm{~s}$ of the ignited release. Mole fraction of hydroxyl in a flame of 0.01 is characteristic for combustion at normal atmospheric conditions thus $\mathrm{OH}$ concentration is an indication of where burning is occurring. In the initial period of the release (up to $0.025 \mathrm{~s}$ ) the burning region is a consequence of the ignition position. CFD has provided an interesting insight into some unusual flow phenomenon occurring within the garage. It can be seen how after 0.25 $\mathrm{s}$ the external flame, exiting the vent appears to "split", whilst later (as seen at $1.78 \mathrm{~s}$ ), when the garage is completely filled with hydrogen the entire vent is filled with burning mixture.
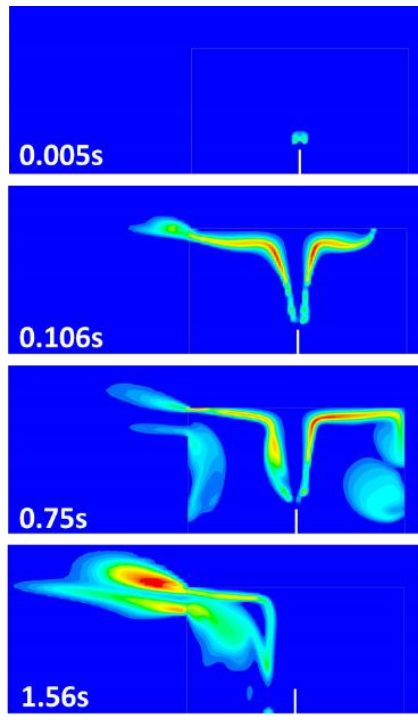
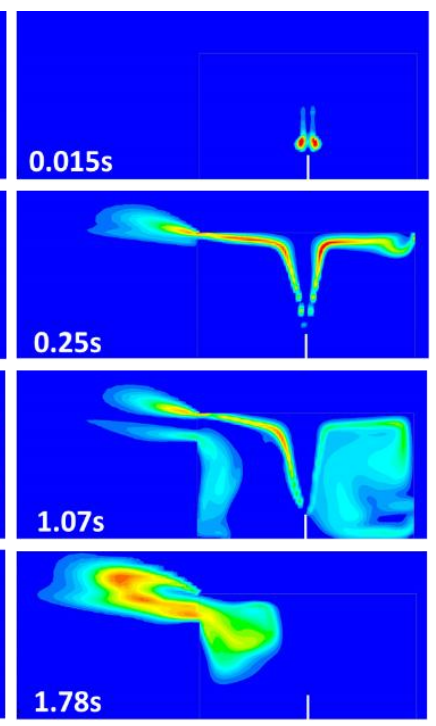
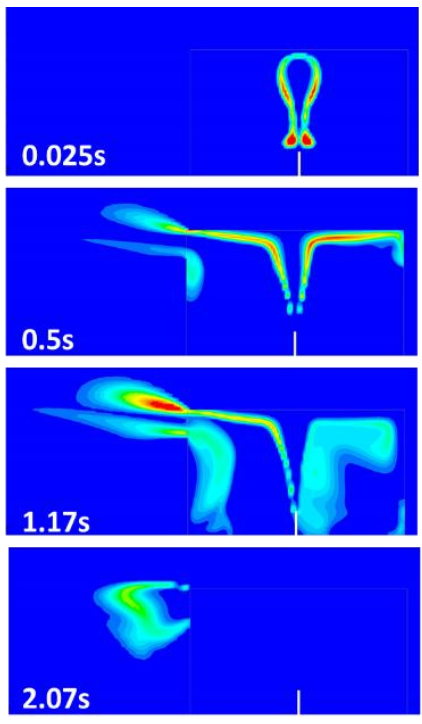

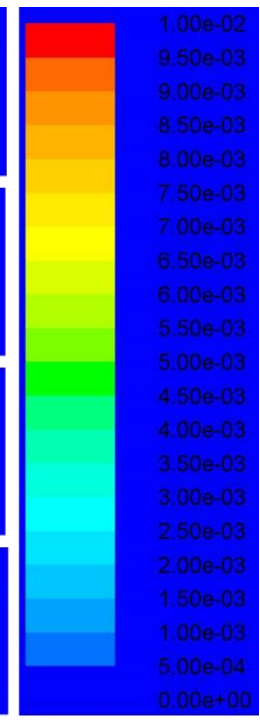

Figure 6. Contours of hydroxyl mole fraction showing dynamics of flame development for the ignited release

In order to explain this "split" of the external flame both horizontal and vertical 2D slices of OH mole fraction through the centre plane of the vent are presented in Figure 7, in addition a 3D image of the flame surface is shown at the same point in time. Figure 7 focuses on the region between $0.25 \mathrm{~s}$ and $0.5 \mathrm{~s}$ where the "split" occurs. In the initial $0.5 \mathrm{~s}$ of the release the flame spreads along the ceiling and down to the vent, in addition the flame spreads along the side walls of the garage to the vent. However, whilst the flame is spreading the growing pressure within the garage causes air to be forced 
out through the vent, in addition to the burning mixture. The resultant flow regime leads to a period of approximately $1 \mathrm{~s}$ where the flow exiting the vent is a combination of pressurised air in the centre of the vent and burning mixture around the top and base of the vent.

Horizontal plane through the vent centre

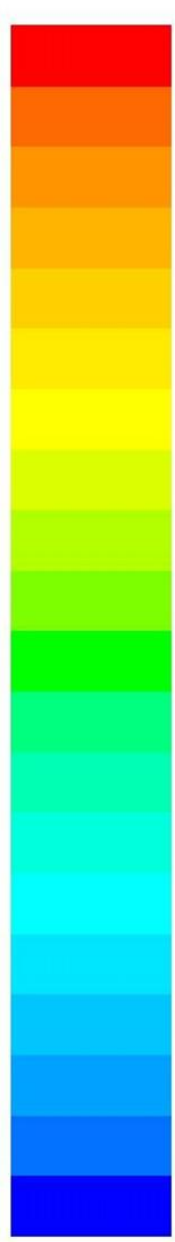

$6.00 \mathrm{e}-04$

$5.00 \mathrm{e}-04$

$4.50 \mathrm{e}-04$

$4.00 \mathrm{e}-04$

$3.50 \mathrm{e}-04$

$3.00 \mathrm{e}-04$

$2.50 \mathrm{e}-04$

2.00e-04

$1.50 \mathrm{e}-04$

$1.00 \mathrm{e}-04$

$5.00 \mathrm{e}-05$
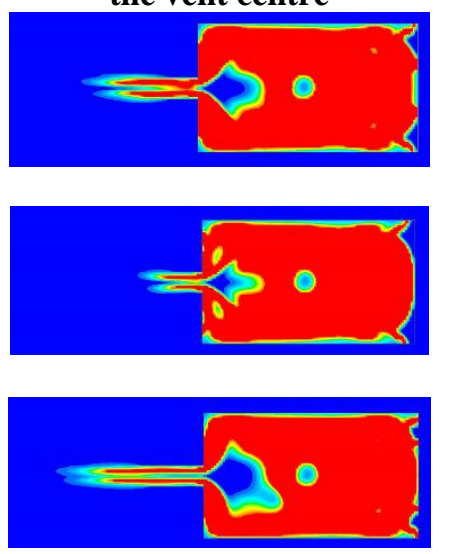

$5.50 \mathrm{e}-04$

$0.00 \mathrm{e}+00$
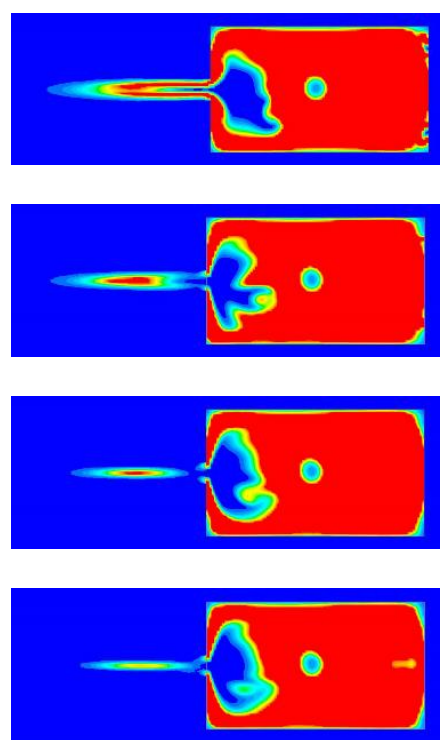

9
Vertical plane through the vent centre

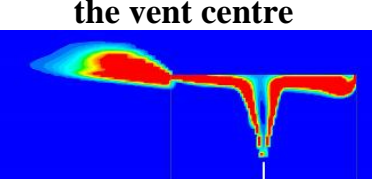

$0.25 \mathrm{~s}$

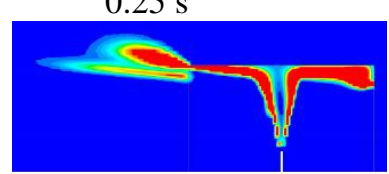

$0.28 \mathrm{~s}$

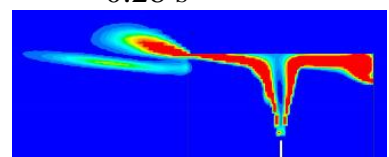

$0.31 \mathrm{~s}$

3D Iso-surface of $\mathrm{OH}$
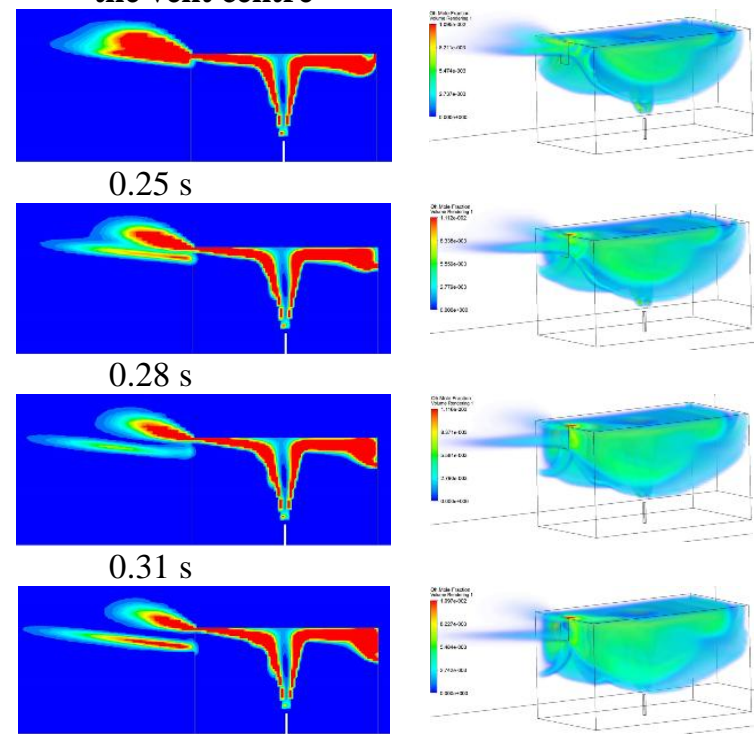

$0.34 \mathrm{~s}$
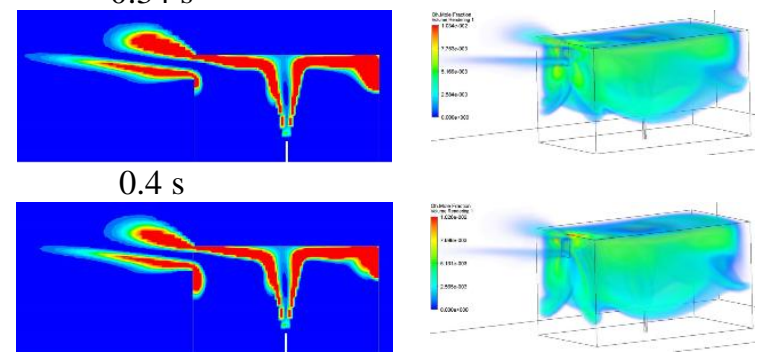

$0.45 \mathrm{~s}$
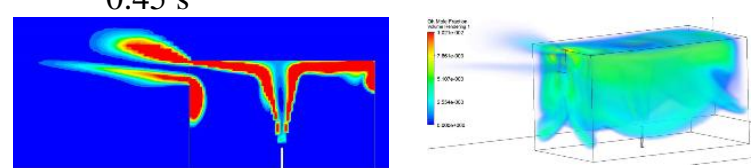
Figure 7. Contours of hydroxyl mole fraction along horizontal and vertical planes through the midpoint of the vent, alongside a 3D iso-surface of hydroxyl mole fraction for the period $0.25-0.51 \mathrm{~s}$

\subsection{Thermal effects and the external flame for the ignited release}

As mentioned the overpressure resulting from the ignited release is the primary safety concern highlighted by this work. However, it can be seen from Figure 6 that in the event of an ignited release within the garage an external flame rapidly develops through the garage vent. This external flame reaches a maximum length of approximately $3 \mathrm{~m}$ around $1.56 \mathrm{~s}$. Clearly, this has implications for surrounding life and infrastructure. But it should be noted that $3 \mathrm{~m}$ is an indication of the flame length, the distance at which there is no danger to a person is longer than this again. Separation distances from an ignited hydrogen leak are discussed in [19]. A temperature of $70^{\circ} \mathrm{C}$ or $343 \mathrm{~K}$ can be taken as a no harm limit at which point there is no danger to people. Temperature contours along a $2 \mathrm{D}$ slice, limited to $343 \mathrm{~K}$ are shown in Figure 8 for the first $1.17 \mathrm{~s}$ of the release. It can be seen how in this time a temperature of $70^{\circ} \mathrm{C}$ is reached at a distance of almost $7 \mathrm{~m}$ from the vent. Beyond this time the garage would be destroyed by overpressure. However, for completeness the temperature contours at $1.56 \mathrm{~s}$ (i.e. when the maximum external flame exists) are shown in Figure 9. It can be seen how the no harm distance is in the region of $9 \mathrm{~m}$. 

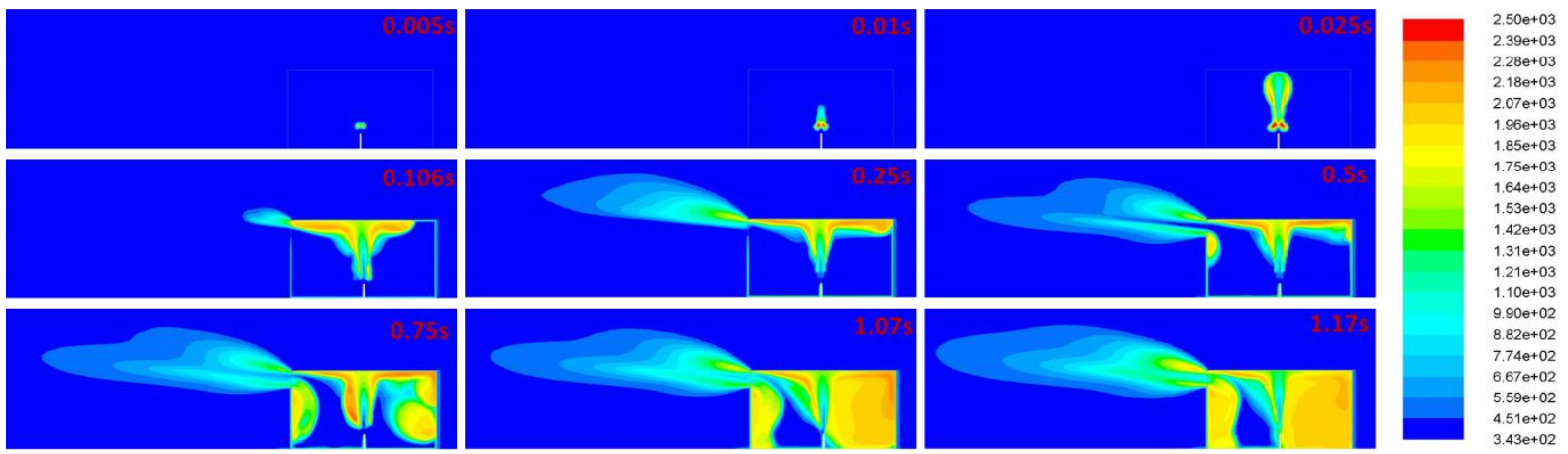

Figure 8 Temperature contours showing "no harm" distance of $70^{\circ} \mathrm{C}$ for the first $1.17 \mathrm{~s}$ of the ignited release. Note garage is $4.5 \mathrm{~m}$ long.
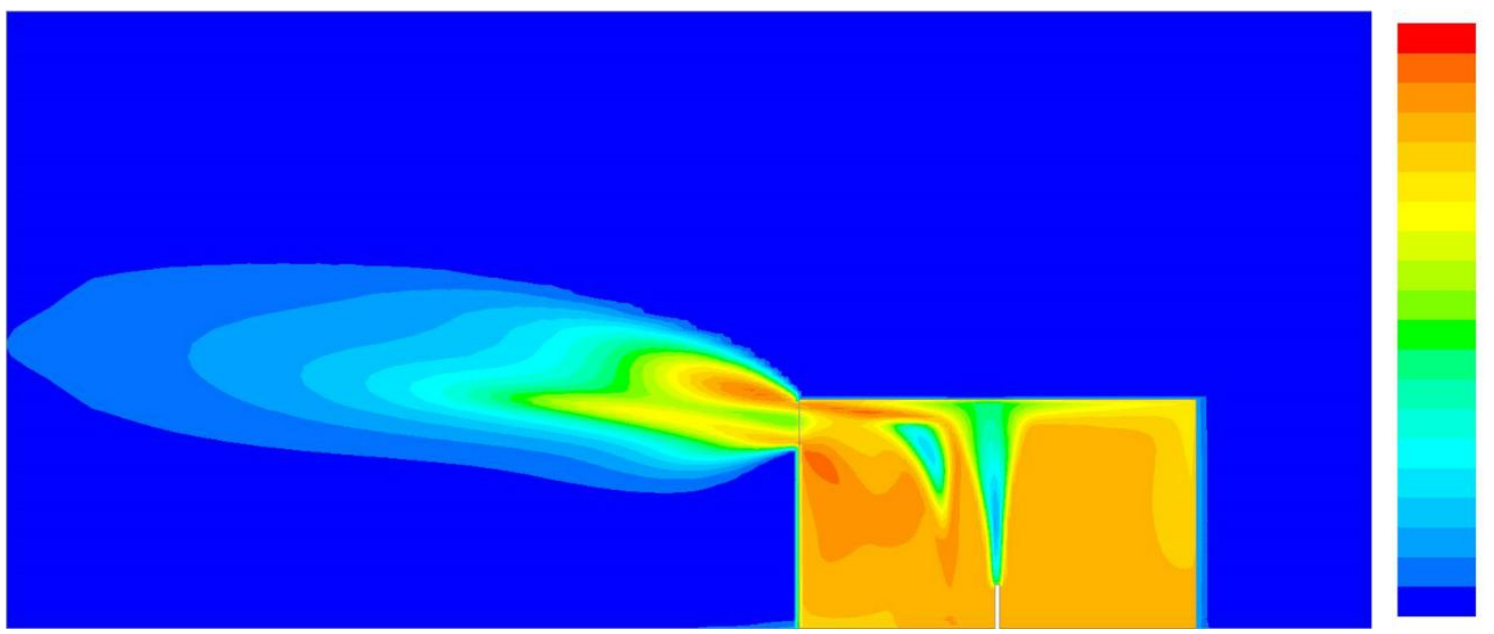

Figure 9 Temperature contours showing "no harm" distance of $70^{\circ} \mathrm{C}$ at $1.56 \mathrm{~s}$ of the ignited release (the point of maximum flamelength). Note garage is $4.5 \mathrm{~m}$ long.

\subsection{CONCLUSIONS}

A hypothetical scenario has been considered where hazards have been investigated, in particular overpressures which arise from the sustained unignited and ignited release from an onboard hydrogen storage tank at 700 bar through a $3.34 \mathrm{~mm}$ diameter orifice, representing the TPRD in a small garage with a single vent equivalent in area to small window. The work has focused on the overpressures arising purely as a result of the ignited and unignited release and the primary fire which may have activated the TPRD has not been included in the analysis. It has been shown how the overpressure predicted in the case of an unignited release using both CFD and an analytical model is in the region of $0.55 \mathrm{kPa}$ and thus unlikely to cause structural damage. However, the overpressure predicted for the ignited release is two orders of magnitude greater, reaching over $55 \mathrm{kPA}$ in less than $1 \mathrm{~s}$ and thus potentially causing destruction of the structure.

In the case that the TPRD malfunctions, rather than being thermally activated, the resultant unignited release is unlikely to cause harm to the structure unless ignited, in which case a significant hazard exists as the garage is engulfed by a flammable atmosphere in less than $1 \mathrm{~s}$. An unignited release is however detrimental for an person within the garage as the oxygen is depleted to levels dangerous to people within this time. In the case of the ignited release, whilst the resultant overpressures are the primary safety concern, it has been shown how the thermal effects resulting from the release extend almost $9 \mathrm{~m}$ from the jet in $1.5 \mathrm{~s}$. 
Further numerical studies are required to investigate the pressure peaking phenomenon for ignited releases in order that safety recommendations can be made. The results presented are the first of their kind and application of this work extends beyond TPRDs and is relevant where there is a rapid, ignited release of hydrogen in an enclosure with limited ventilation

\subsection{REFERENCES}

[1] http://www.hyindoor.eu/

[2] Fuster B, Houssin-Agbomson D, Jallais S, Vyazmina E, Dang-Nhu G, Bernard-Michel G, et al. Guidelines and recommendations for indoor use of fuel cells and hydrogen systems. Int $\mathbf{J}$ Hydrogen Energy 2017;42:7600-7. doi:10.1016/j.ijhydene.2016.05.266.

[3] Hooker, P., Hall, J., Hoyes, J.R., Newton, A. and Willoughby, D., 2017. Hydrogen jet fires in a passively ventilated enclosure. International Journal of Hydrogen Energy, 42(11), pp.75777588.

[4] Commission Regulation (EU) No 406/2010 of 26 April 2010 implementing Regulation (EC) No, Council 79/2009 of the European Parliament and of the. Type-approval of hydrogenpowered motor vehicles. 2010.

[5] Brennan S, Makarov D, Molkov V. Dynamics of Flammable Hydrogen-Air Mixture Formation in an Enclosure with a Single Vent. Sixth Int Semin Fire Explos Hazards 2011:978-81. doi:10.3850/978-981-08-7724-8.

[6] Brennan S, Molkov, V. Safety assessment of unignited hydrogen discharge from onboard storage in garages with low levels of natural ventilation. Int J Hydrogen Energy 2013. doi:10.1016/j.ijhydene.2012.08.036.

[7] Molkov, V., Makarov, D. and Bragin, M. Physics and modelling of underexpanded jets and hydrogen dispersion in atmosphere, 2009.

[8] Makarov D, Shentsov V, Kuznetsov M, Mokov, V. Pressure peaking phenomenon: model validation against unignited release and jet fire experiments. International Journal of Hydrogen Energy, Volume 43, Issue 19, 10 May 2018, Pages 9454-9469

[9] Molkov, V. and Saffers, J.B., 2013. Hydrogen jet flames. International journal of hydrogen energy, 38(19), pp.8141-8158.

[10] Kuznetsov, M., Shentsov, V., Brennan, S. and Molkov, V. Experimental and Analytical Study of Hydrogen Jet Fire in a Vented Enclosure. Eighth Int. Semin. Fire Explos. Hazards, 2016, p. $0-9$.

[11] http://www.ansys.com/Products/Fluids/ANSYS-Fluent

[12] Ferzieger J. L. and Peric. M. Computational Methods for Fluid Dynamics. Springer-Verlag, Heidelberg.: 1996.

[13] Issa RI. Solution of the implicitly discretised fluid flow equations by operator-splitting. J Comput Phys 1986. doi:10.1016/0021-9991(86)90099-9.

[14] Magnussen BF. The Eddy Dissipation Concept- A Bridge Between Science and Technology. ECCOMAS Themat. Conf. Comput. Combust., 2005.

[15] Molkov V, Shentsov V, Brennan S, Makarov D. Hydrogen non-premixed combustion in enclosure with one vent and sustained release: Numerical experiments. Int J Hydrogen Energy 2014;39:10788-801. doi:10.1016/j.ijhydene.2014.05.007.

[16] Emmons DD. Vent flows. In: Di Nenno P. J., editor. SFPE Handbook, ed. 2nd Editio, Boston, MA, USA: Society of Fire Protection Engineers; 1995.

[17] Baker, W. E., Cox, P. A., Westine, P. S., Kulesz, J. J. A, Strehlow RA. Explosion Hazards and Evaluation. Amsterdam, The Netherlands: Elsevier Scientific Publishing Co.; 1983.

[18] NASA. Safety standard for hydrogen and hydrogen systems. 1997.

[19] Molkov V. Fundamentals of Hydrogen Safety Engineering I. eBooks and textbooks from bookboon. com.; 2012. 